\title{
Injuries Reported by Selected Health Facilities During the Arbaeenia Mass Gathering at Babel Governorate, Iraq, 2014: Retrospective Records Analysis
}

Abdulaal Chitheer ${ }^{1}$, MBChB, DFE; Faris Lami ${ }^{2}, \mathrm{MBChB}, \mathrm{PhD}, \mathrm{FFPH} ;$ Ahmed Radhi ${ }^{3}$, MBChB, FICMS; Ali Arbaji ${ }^{4}$, MD

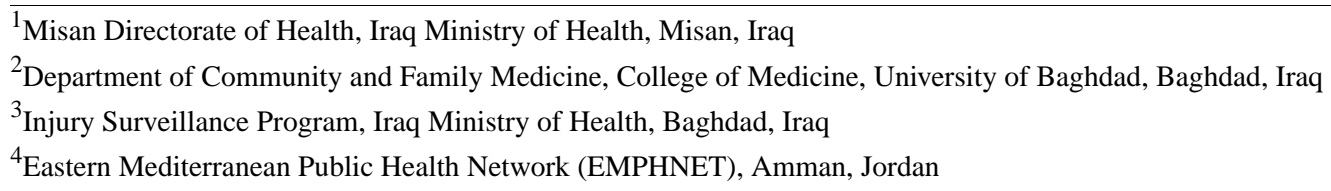

Corresponding Author:

Faris Lami, MBChB, PhD, FFPH

Department of Community and Family Medicine

College of Medicine

University of Baghdad

Baghdad College of Medicine

Baghdad, 00964

Iraq

Phone: 9647901402692

Email: farislami@gmail.com

\section{Abstract}

Background: Arbaeenia is the largest religious mass gathering in Iraq. The conditions associated with mass gatherings result in high rates of injury. There have been no prior studies on injuries during the Arbaeenia mass gathering.

Objective: This study describes the injuries observed during the Arbaeenia mass gathering in Babel Governorate in Iraq between November 24 and December 14, 2014.

Methods: The study was conducted in Babel Governorate at the emergency departments of six public hospitals and two major temporary medical units that were located along the three roads connecting the Middle and Southern Iraqi governorates. We used the Iraq Injury Surveillance System modified form to collect information on injured patients treated in the selected facilities. Data on fatal injuries was obtained from the coroner's office. The following data were collected from the patients: demographics, outcome of injury, place and time of occurrence, mode of evacuation and medical care before arriving at the hospital, duration of travel from place of occurrence to hospital, disposition of non-fatal injury, cause and mode of injury, and whether the injury occurred in connection with the Arbaeenia mass gathering.

Results: Information was collected on 1564 injury cases, of which 73 were fatal. About half of the reported nonfatal injuries, $687 / 1404(48.9 \%)$, and a quarter of fatalities, $18 / 73(25 \%)$ were related to the Arbaeenia mass gathering $(P<.001)$. Most of the reported injuries were unintentional, 1341/1404 (95.51\%), occurred on the street, 864/1323 (65.6\%), occurred during the daytime $1103 / 1174(93.95 \%)$. Most of those injured were evacuated by means other than ambulance 1107/1206 (91.79\%) and did not receive pre-hospital medical care 788/1163 (67.7\%). Minor injuries 400/1546 (25.9\%) and traffic accidents 394/1546 (25.5\%) were the most common types of injuries, followed by falls 270/1546 (17.5\%). Among fatal injuries, traffic accidents 38/73 (52\%) and violence $18 / 73(25 \%)$ were the leading causes of death. Mass gathering injuries were more likely to occur among individuals aged 21-40 years (odds ratio [OR] 3.5; 95\% CI 2.7-4.5) and >41 years (OR 7.6; 95\% CI 5.4-10.6) versus those <21 years; more likely to be unintentional than assault (OR 5.3; 95\% CI 1.8-15.5); more likely to happen on the street versus at home (OR 37.7; 95\% CI 22.4-63.6); less likely to happen at night than during the day (OR 0.2; 95\% CI 0.1-0.4); and less likely to result in hospital admission (OR 0.5; 95\% CI 0.3-0.7).

Conclusions: The study shows that most injuries were minor, unintentional, and nonfatal, and most people with injuries had limited access to ambulance transportation and did not require hospitalization. 
(JMIR Public Health Surveill 2020;6(2):e10877) doi: 10.2196/10877

\section{KEYWORDS}

mass gathering; Injury; Karbala, Iraq

\section{Introduction}

Mass gatherings are defined as events with an attendance of more than 1000 persons or as events attended by more than 25,000 people [1]. Injuries that occur during mass gatherings are often due to overcrowding, stampedes, terrorism, and spiritual acts [2,3]. Injuries and noncommunicable diseases are responsible for more deaths and morbidity during mass gatherings than communicable diseases [4].

During the annual Hajj, trauma is a major cause of injury and death. Pilgrims walk long distances through or near dense traffic and motor vehicle accidents are inevitable; however, the most feared trauma hazard is a stampede [5]. In Iraq, injuries are the second leading cause of death and violence, while road traffic, fire, and drowning are among the main causes of injury-related deaths [6,7]. In 2010, the Iraq Injury Surveillance System (IISS) was established in major hospitals and coroners' offices to enable timely electronic reporting of injuries. Al-Hilla hospital, a major referral hospital in Babel Governorate, and the Babel Coroner's Office were added to the roll of IISS reporting facilities in 2013 [8].

The ability of the Iraq health system to respond to injuries is challenged during mass gatherings, during which the risk of injury increases. The Arbaeenia mass gathering is the largest gathering of Shia Muslims worldwide and occurs annually in Karbala, Iraq. During this mass gathering, approximately 20 million pilgrims from nearly 40 countries attend the ceremony $[9,10]$. Many of the pilgrims travelling to Karbala walk a distance of up to 600 kilometers through several Iraqi governorates, and millions of Arbaeenia attendees pass through Babel Governorate along the three roads connecting Middle and Southern Iraqi governorates to Babel.

There are few studies on the public health problems associated with mass gatherings [11]. During a mass gathering, road traffic injuries and terrorism are major risks to the health of pilgrims and the local community [12]. Because of cultural or religious beliefs, some attendees practice self-harm such as laceration of their scalp using sharp knives and other risky practices [11]. There is particularly limited information available on injury surveillance systems at mass gatherings [13]. The importance of developing public health surveillance system in mass gatherings has been emphasized in recommendations from previously published reports $[12,14]$. Public health for mass gatherings health is an evolving niche of prehospital care rooted in emergency medicine, emergency management, public health, and disaster medicine [15].

This study describes the mass gathering injuries reported at selected health facilities in Babel Governorate in Iraq during the Arbaeenia mass gathering in 2014.

\section{Methods}

We conducted this study in Babel Governorate between November 24, 2014 and December 14, 2014. The emergency departments (ED) of six public hospitals in six districts and two major temporary medical units were selected for convenient data collection. The selected facilities were located along the three roads connecting the Middle and Southern Iraqi governorates to Babel Governorate.

We used an IISS modified form to collect information on injury cases treated in the selected facilities. Data on fatal injuries were obtained from the coroner's Office in IISS sentinel sites in the selected areas. The following data were collected: patient demographics, injury outcome, place and time of occurrence, mode of evacuation and medical care before arriving the hospital, duration of travel from place of occurrence to hospital, disposition of nonfatal injury, cause and mode of injury, and association with the Arbaeenia mass gathering.

Data entry was performed using Epi Info and SPSS Statistics was used for data analysis. We estimated the injury frequencies and percentages by demographics and odds ratios of the factors associated with injuries at the mass gathering. Chi-square statistics were used to test significance at $P<.05$. We estimated the 3-period moving average for the daily trend of fatal and nonfatal injuries to remove trend fluctuations.

\section{Results}

There were 1564 injuries treated in the health facilities selected for this study. Of these, 687/1404 (48.9\%) were injuries related to the Arbaeenia mass gathering; of the $73(5 \%)$ fatal injuries, $18 / 73(25 \%)$ were related to the mass gathering. The majority of the injuries, 1096/1564 (70.1\%), were collected from the ED of six public hospitals, 395/1564 (25.2\%) were from the two temporary health facilities, and 73/1564 (5\%) were from the coroners' offices. A major proportion of victims were aged less than 21 years old $(44.8 \%, 685 / 1564), 72.6 \%$ (1136/1564) were males, and $63.4 \%(955 / 1564)$ were residents of Babel Governorate (Table 1). 
Table 1. Demographics of patients with sustained injuries during the Arbaeenia mass gathering in Babel Governorate, Iraq, $2014(\mathrm{~N}=1564)^{\mathrm{a}}$.

\begin{tabular}{|c|c|}
\hline Characteristics & $\mathrm{n}(\%)$ \\
\hline \multicolumn{2}{|l|}{ Reporting sites } \\
\hline Hospitals (emergency departments) & $1096(70.1)$ \\
\hline Temporary health care facilities & $395(25.3)$ \\
\hline Coroner's office & $73(4.7)$ \\
\hline Total & 1564 \\
\hline \multicolumn{2}{|l|}{ Injury related to mass gathering } \\
\hline Yes & $687(48.9)$ \\
\hline No & $717(51.1)$ \\
\hline Total & 1404 \\
\hline \multicolumn{2}{|l|}{ Age groups (years) } \\
\hline$<21$ & $685(43.8)$ \\
\hline $21-40$ & $571(36.5)$ \\
\hline$\geq 41$ & $279(17.9)$ \\
\hline Total & 1535 \\
\hline \multicolumn{2}{|l|}{ Sex } \\
\hline Male & $1136(72.6)$ \\
\hline Female & $428(27.4)$ \\
\hline Total & 1564 \\
\hline \multicolumn{2}{|l|}{ Place of residence } \\
\hline Babel Governorate & $955(63.4)$ \\
\hline Other Iraqi Governorates & $534(35.4)$ \\
\hline Other countries (Iran, Saudi Arabia, Turkey, Afghanistan) & $17(1.2)$ \\
\hline Total & 1506 \\
\hline
\end{tabular}

a Totals may be $<1564$ due to missing data.

Table 2 shows the location and time of injuries, factors related to medical services, and relationship to the mass gathering. Most injuries $(864 / 1564,55.2 \%)$ occurred on the street and 580/680 $(67.2 \%)$ of these were mass gathering-related. Approximately $93.9 \%$ (1103/1174) of injuries occurred during the day, and $605 / 619(54.9 \%)$ of these associated with the mass gathering. The injuries were predominantly unintentional 1341/1404 (95.5\%). Only $17 / 1404(1 \%)$ of injuries were intentional (self-inflicted) and 16/687 (94\%) of these were related to the mass gathering. Ambulance services were used for only 99/1206 (8\%) of injuries, whereas 661/1206 (54.8\%) and 446/1206 $(36.9 \%)$ were transported in other vehicles or carried directly by people to the hospital. The majority $749 / 1186(63.2 \%)$ of the injured people reached the hospital within an hour of injury, 258/1186 (21.7\%) reached between 2 hours and 24 hours, and $179 / 1186(15.1 \%)$ reached after $>24$ hours. Of the injuries that reached the hospital after more than an hour, 208/623 (80.6\%) $-168 / 623(93.9 \%)$ were injuries related to the mass gathering. Only $375 / 1163(32.3 \%)$ of injuries were medically treated before reaching the hospital, 333/603 $(88.8 \%)$ of these associated with the mass gathering; and 148/1133 (11\%) of injuries were admitted to the hospital, 55/667 (38\%) of these were related to the mass gathering.
The moving average daily trend for nonfatal injuries showed a gradual increase from the start of the study on November 24 and peaked on December 8, then declined prior to the day of the Arbaeenia celebration (December 13, 2014). The daily trend for fatal injuries was constant throughout the period, using the moving average (Figure 1).

Figure 2 shows the distribution of injury causes. Of the fatal injuries, $52 \%$ were due to traffic accidents and $25 \%$ were due to gun violence. Of the nonfatal accidents, the leading causes were injuries related to walking (27\%), traffic accidents (24\%), and falls $(18 \%)$.

Table 3 shows the factors associated with injuries incurred during the Arbaeenia mass gathering injuries. Fatal injuries were less likely to be associated with the mass gathering (OR 0.3 ; 95\% CI 0.2-0.4) compared to nonfatal injuries. Compared to the people in the $<21$ years age group, those $21-40$ years of age (OR 3.5; 95\% CI 2.7-4.8) and $>40$ years of age (OR 7.6; $95 \%$ CI 5.4-10.6) were more likely to be injured in the mass gathering. Injuries among women were more likely to be associated with the mass gathering (OR 1.4; 95\% CI 1.1-1.8). Compared to injuries from assault, self-inflicted and unintentional injuries were more likely to be associated with 
the mass gathering (self-inflicted: OR 88, 95\% CI 9-863; unintentional: OR 5.3, 95\% CI 1.8-15.5). Compared to injuries that occurred at home, injuries that occurred in the street, at work, and elsewhere were more likely to be associated with the mass gathering (OR 37.7, 95\% CI 22.4-63.6; OR 25.7, 95\% CI 14.1-47.3; and OR 9.2, 95\% CI 2.5-33.8, respectively). Injuries that occurred at night were less likely to be mass gathering-related than those that occurred during the day (OR 0.2 ; $95 \%$ CI $0.1-0.4)$. MG injuries were more likely to be evacuated by other means (e.g., carried by humans; OR 19.8,
95\% CI 11-35.8) than by ambulance. People with injuries who took 2-24 hours and $>24$ hours to reach a hospital were more likely to have mass-gathering-related injuries (OR 8.5; 95\% CI 6-11.9 versus OR 31; 95\% CI 16.6-58.2), compared to those with injuries who reached a facility in $<2$ hours. Injuries that received medical care before reaching the hospital were more likely to be mass gathering-related than those that did not receive medical care (OR 15.2, 95\% CI 11.1-20). Injuries admitted to the hospital were less likely to be mass gathering-related than those not admitted (OR 0.5, 95\% CI 0.3-0.7). 
Table 2. Injury characteristics and relationship to the Arbaeenia mass gathering in Babel Governorate, Iraq, 2014 (N=1564).

\begin{tabular}{|c|c|c|c|}
\hline \multirow[t]{2}{*}{ Variables } & \multicolumn{3}{|c|}{ Relationship to the mass gathering } \\
\hline & Yes $(\%)$ & No $(\%)$ & Total $^{\mathrm{a}} \mathrm{n}(\%)$ \\
\hline \multicolumn{4}{|l|}{ Place of occurrence } \\
\hline Home & $16(5.2)$ & $294(94.8)$ & $310(23.4)$ \\
\hline Street & $580(67.2)$ & $864(32.8)$ & $864(55.2)$ \\
\hline Workplace & $80(58.4)$ & $57(41.6)$ & $137(10.3)$ \\
\hline Others & $4(33.3)$ & $8(66.7)$ & $12(1.1)$ \\
\hline Total & $680(51.4)$ & $643(48.6)$ & $1323(100)$ \\
\hline \multicolumn{4}{|l|}{ Time of occurrence } \\
\hline Day time (6 am to $5 \mathrm{pm})$ & $605(54.9)$ & $498(45.1)$ & $1103(93.9)$ \\
\hline Nighttime ( $6 \mathrm{pm}$ to $5 \mathrm{am})$ & $14(19.7)$ & $57(80.3)$ & $71(6.1)$ \\
\hline Total & $619(52.8)$ & $555(47.2)$ & $1174(100)$ \\
\hline \multicolumn{4}{|l|}{ Cause of injury } \\
\hline Assault & $4(15.4)$ & $22(84.6)$ & $26(1.8)$ \\
\hline Intentional & $16(94.1)$ & $1(5.9)$ & $17(1.2)$ \\
\hline Unintentional & $658(49.1)$ & $683(50.9)$ & $1341(95.5)$ \\
\hline Unknown & $9(45.0)$ & $11(55.0)$ & $20(1.5)$ \\
\hline Total & $687(48.9)$ & $717(51.1)$ & $1404(100)$ \\
\hline \multicolumn{4}{|l|}{ Mode of evacuation } \\
\hline Ambulance & $50(50.5)$ & $49(49.5)$ & $99(8.3)$ \\
\hline Other vehicles & $171(25.9)$ & $484(74.1)$ & $661(54.8)$ \\
\hline Other means (carried by people) & $425(95.3)$ & $21(4.7)$ & $446(36.9)$ \\
\hline Total & $646(53.6)$ & $560(46.4)$ & $1206(100)$ \\
\hline \multicolumn{4}{|l|}{ Prehospital time interval (hours) } \\
\hline 1 & $247(33.0)$ & $502(67.0)$ & $749(63.2)$ \\
\hline $2-24$ & $208(80.6)$ & $50(19.4)$ & $258(21.7)$ \\
\hline$>24$ & $168(93.9)$ & $11(6.1)$ & $179(15.1)$ \\
\hline Total & $623(52.5)$ & $563(47.5)$ & $1186(100)$ \\
\hline \multicolumn{4}{|l|}{ Prehospital medical care } \\
\hline Not received & $270(34.3)$ & $518(65.7)$ & $788(67.7)$ \\
\hline Received & $333(88.8)$ & $42(11.2)$ & $375(32.3)$ \\
\hline Total & $603(51.8)$ & $560(48.2)$ & $1163(100)$ \\
\hline \multicolumn{4}{|l|}{ Disposition of nonfatal injuries } \\
\hline Not admitted (treated and discharged) & $585(55.7)$ & $468(44.3)$ & $1053(79)$ \\
\hline Admitted $^{\mathrm{b}}$ & $55(37.8)$ & $93(62.2)$ & $148(11)$ \\
\hline Unknown & $27(20.8)$ & $103(79.2)$ & $130(10)$ \\
\hline Total & $667(50.2)$ & $664(49.8)$ & 1331 \\
\hline
\end{tabular}

${ }^{\mathrm{a}}$ Totals differ due to missing data or lack of response.

${ }^{\mathrm{b}}$ Including self-discharged and referred. 
Figure 1. Trend of reported injuries during Arbaeenia mass gathering in Babel Governorate, Iraq, 2014 (N=1561).

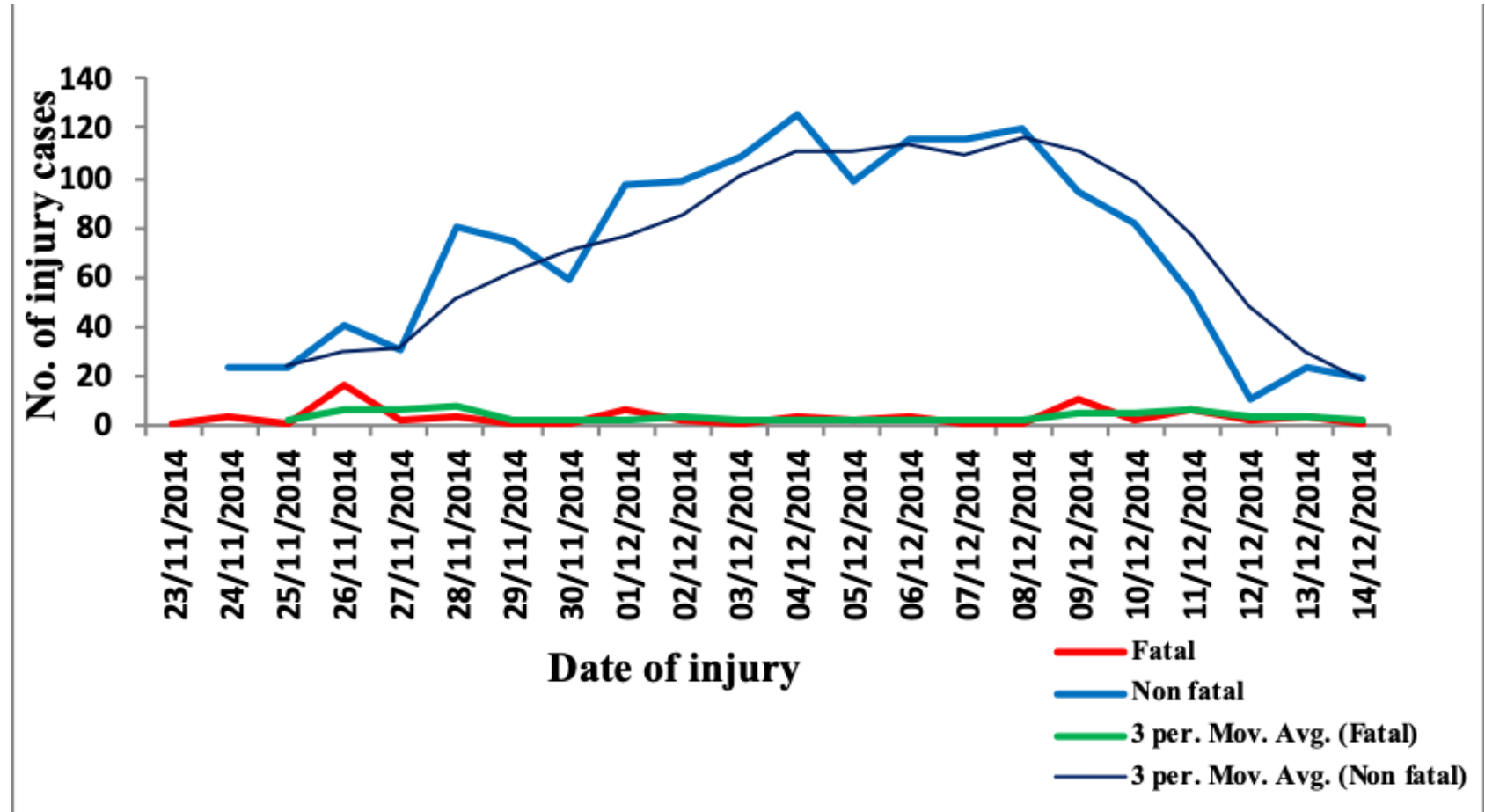

Figure 2. Distribution of causes of injuries by outcome during the Arbaeenia mass gathering in Babel Governorate, Iraq, 2014 (N=1564).

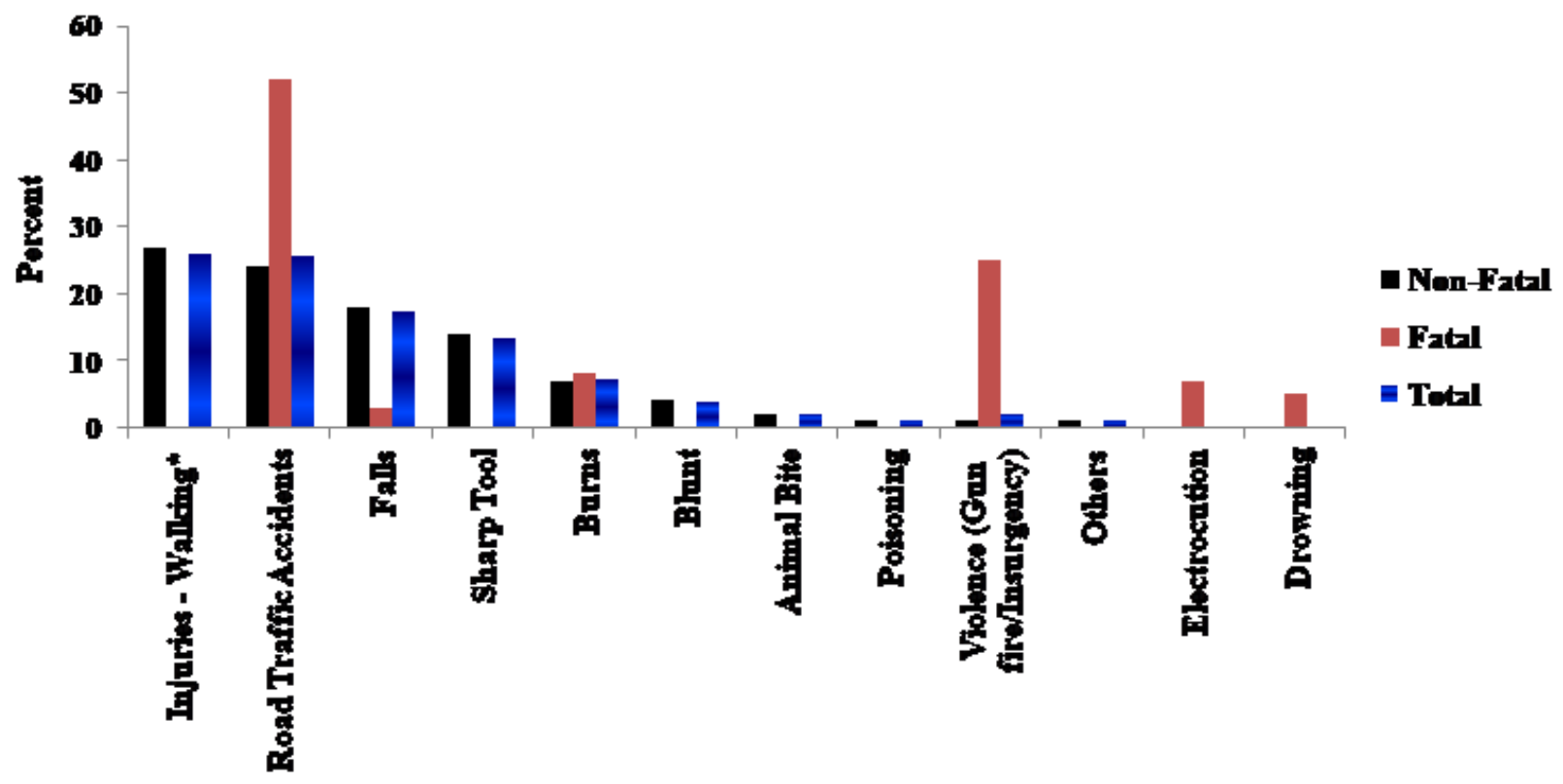

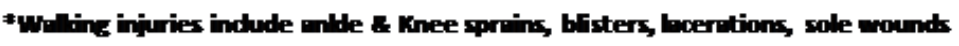


Table 3. Factors associated with injuries occurring during the Arbaeenia mass gathering in Babel Governorate, Iraq, 2014 (N=1564)

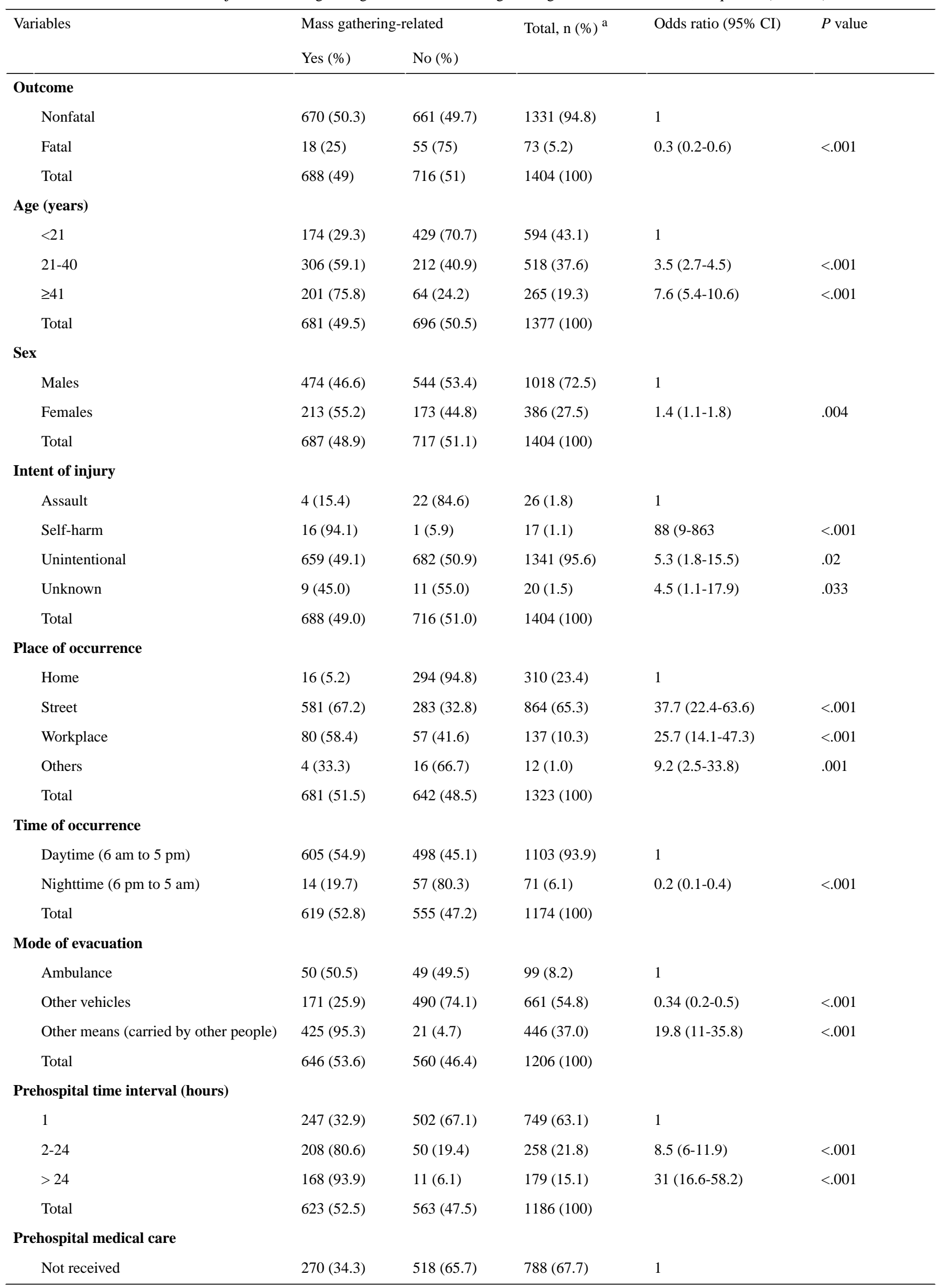




\begin{tabular}{|c|c|c|c|c|c|}
\hline \multirow[t]{2}{*}{ Variables } & \multicolumn{2}{|c|}{ Mass gathering-related } & \multirow[t]{2}{*}{ Total, $\mathrm{n}(\%)^{\mathrm{a}}$} & \multirow[t]{2}{*}{ Odds ratio $(95 \% \mathrm{CI})$} & \multirow[t]{2}{*}{$P$ value } \\
\hline & Yes $(\%)$ & No $(\%)$ & & & \\
\hline Received & $333(88.8)$ & $42(11.2)$ & $375(32.3)$ & $15.2(11.1-20)$ & \\
\hline Total & $603(51.8)$ & $583(48.2)$ & $1163(100)$ & & $<.001$ \\
\hline \multicolumn{6}{|l|}{ Disposition of nonfatal injuries } \\
\hline Not admitted (treated and discharged) & $586(55.7)$ & $467(44.3)$ & $1053(79.1)$ & 1 & \\
\hline Admitted & $56(37.8)$ & $92(62.2)$ & $148(11.1)$ & $0.5(0.3-0.7)$ & $<.001$ \\
\hline Unknown & $27(20.8)$ & $103(79.2)$ & $130(9.8)$ & $0.2(0.2-0.3)$ & $<.001$ \\
\hline Total & $669(48.9)$ & $464(51.1)$ & $1331(100)$ & & \\
\hline
\end{tabular}

${ }^{\mathrm{a}}$ Totals are different due to missing data or lack of response.

\section{Discussion}

The study describes injuries reported at several health facilities during the Arbaeenia mass gathering in Babel Governorate, Iraq. Most of the injuries were minor (walking-related), unintentional, or nonfatal with limited or no access to ambulance transportation and the affected people did not require hospitalization. The injured individuals often reached a hospital within an hour of injury. People with injuries who took more than 1 hour to reach a hospital but received medical care prior to arrival were more common among people with injuries associated with the mass gathering than those that were not.

During mass gatherings, trauma is one of the most common medical problems [16]. The health consequences of mass gatherings include injuries resulting from crowd density and inadequate infrastructure, exposure to extreme weather events, and escalation of violence as a result of crowd behavior [17]. The injured patients during the Arbaeenia mass gathering were mostly young, consistent with the global figures on injuries [18]. Youth are more likely to take risks than older individuals, increasing their risk of injury [19]. Unintentional injuries accounted for the vast majority of cases reported, which was consistent with the findings of global and national injury surveillance reports [8].

In contrast to reports from IISS data and other sources, this study found that nearly two-thirds of the injuries occurred in the street, as opposed to in the home [8,20,21]. The high occurrence of injuries in the street is a result of the nature of the mass gathering, during which pilgrims travel long distances on foot to attend the event in Karbala.

Few of the injuries were transported to the hospital by ambulance, which could explain the lack of prehospital medical care for the majority of injuries. Despite the lack of ambulance services to evacuate the injuries, the majority of patients reached a health care facility within an hour of injury, which trauma experts consider the critical timeframe for lifesaving efforts. In general, few injury victims receive prehospital medical care and ambulance transportation [22,23]. This study showed that people with injuries related to the mass gathering were less likely to reach the hospital within the critical 1-hour timeframe. Road congestion during the mass gathering may have delayed patients in reaching the hospitals. The majority of injured patients did not require hospitalization, consistent with other religious mass gatherings and injury surveillance reports [8,11,23,24].

The ratio of injury deaths to hospital admissions and ED attendants in this study was $1: 2.7: 15.7$, whereas the IISS report cited a ratio 1:1.5 6 [8]. Our study included minor injuries, which comprised the majority of mass gathering-related injuries, possibly increasing the observed ER burden. Traffic accidents, which accounted for half of injury deaths and a quarter of nonfatal injuries, may also have contributed to the high admission ratio. Hospital admission rates depend on the severity of injury, access to hospital services, and health system structure [25].

The majority of injuries occurred during the daytime, which is consistent with information observed in the IISS report and other studies $[8,19,26]$. The high occurrence of injuries during the daytime may be explained by the high traffic volume during the day. The pilgrims walk during the day and often rest in the evening, which reduces their risk of traffic accidents during the night.

Injuries among women were more likely to be mass gathering-related than those among men. Burns are common among females in Iraq and worldwide, as women have higher exposure to heat or hot surfaces during cooking, and probably this is the case in mass gathering. In contrast, men are mostly the victims of the traffic accident injuries [8,24,27].

Traffic accidents are the leading cause of fatal injuries in Iraq and globally [6]. Traffic accidents accounted for more than half of the fatal injuries in this study, which is higher than the global figures on fatal injuries (24\%) [28]. This may be due to the large number of pilgrims traveling on foot and the high traffic volume on the roadways. A review of studies in low-to-middle-income countries revealed that traffic accidents accounted for one-third to four-fifths of traumatic injury admissions, one-tenth to one-third of all injuries treated in hospitals, and almost half of all bed occupancies in surgical wards [26]. This study showed similar findings on injuries treated in hospitals.

Most of the injuries reported were minor (75\%), which is consistent with prior reports on injuries related to other mass gatherings and may explain why the majority of the injury cases were not admitted to the hospitals [29]. This information is consistent with a study among Iranian pilgrims during the Hajj mass gathering [30-32]. 
This study had several limitations. Some potential subjects may have been missed during data collection. In addition, data for some items, particularly the disposition variable, were missing. Injury data were not collected from all health facilities, which limits generalizability. Injury data collected from health facilities may have underestimated the total injuries that occurred because individuals with minor injuries may not seek medical care from the health facilities [33]. Injury rates could not be calculated, because the population at risk is unknown and could not be determined.

\section{Conflicts of Interest}

None declared.

\section{References}

1. Arbon P. The Development of a Web-based Algorithm for the Prediction of Patient Presentation Rates at Mass Gatherings. Aust J Emerg Manag 2002 Oct;17(1):60-64 [FREE Full text]

2. Ahmed QA, Arabi YM, Memish ZA. Health risks at the Hajj. The Lancet 2006 Mar;367(9515):1008-1015. [doi: 10.1016/s0140-6736(06)68429-8]

3. Burkle FM, Hsu EB. Ram Janki Temple: understanding human stampedes. The Lancet 2011 Jan;377(9760):106-107. [doi: 10.1016/s0140-6736(10)60442-4]

4. Hsieh Y, Ngai KM, Burkle FM, Hsu EB. Epidemiological Characteristics of Human Stampedes. Disaster med. public health prep 2013 Apr 08;3(4):217-223. [doi: 10.1097/dmp.0b013e3181c5b4ba]

5. khorasani-Zavareh D, Dadgari F, Karampourian A, Nouri F. Deaths and Injuries in Hajj: An Important Implication for Mass Gathering Management. Trauma Mon 2016 Dec 03;In press(In press). [doi: 10.5812/traumamon.40790]

6. http://www.moh.gov.iq/upload/upfile/ar/rep2010.pdf. Iraq Ministry of Health, Annual Report 2010 URL: http://www. moh.gov.iq/upload/upfile/ar/rep2010.pdf) [accessed 2015-01-02]

7. Institute FHM. http://www.healthdata.org/sites/default/files/files/country_profiles/GBD/ihme_gbd_country_report_iraq.pdf. Global burden of diseases, injuries, and risk factors study 2010, Iraq profile URL: http://www.healthdata.org/sites/default/ files/files/country profiles/GBD/ihme gbd country report iraq.pdf) [accessed 2015-03-14]

8. Radhi AH. Iraqi injury surveillance system; Triennial Report: 2010-2012. In: https://moh.gov.iq/upload/upfile/ar/345.pdf. Iraq: Iraq Ministry of Health; Feb 01, 2015.

9. Lizzie Dearden. Independent. 2014. One of the world's biggest and most dangerous pilgrimages is underway URL: https:/ /www.independent.co.uk/news/world/middle-east/one-of-the-worlds-biggest-and-most-dangerous-pilgrimagesis-underway-9882702.html [accessed 2014-11-20]

10. Wikipedia. List of largest peaceful gatherings in history. 2014 Nov 25. URL: http://en.wikipedia.org/wiki/ List_of_largest_peaceful_gatherings_in_history

11. Al Lami F, Al Fatlawi A, Bloland P, Nawwar A, Jetheer A, Hantoosh H, et al. Pattern of morbidity and mortality in Karbala hospitals during Ashura mass gathering at Karbala, Iraq, 2010. East Mediterr Health J 2013 Dec 01;19(Supp. 2):13-18. [doi: 10.26719/2013.19.supp2.s13]

12. Health Organization. Report on the Workshop for Health preparedness at mass gatherings, 2012. 2012. URL: http://www. emphnet.net/portals/0/Images/Projects/MG/WHOCountryOfficeIraqReportNov2012.pdf

13. Zeitz K, Zeitz C, Arbon P, Cheney F, Johnston R, Hennekam J. Practical Solutions for Injury Surveillance at Mass Gatherings. Prehosp. Disaster med 2012 Jun 28;23(1):76-81. [doi: 10.1017/s1049023x00005628]

14. Al Nsour M, Fleischauer A. Public health considerations for mass gatherings in the Middle East and North Africa [MENA] region. East Mediterr Health J 2013 Dec 01;19(Supp. 2):42-46. [doi: 10.26719/2013.19.supp2.s42]

15. Guy A, Prager R, Turris S, Lund A. Improving Data Quality in Mass-Gatherings Health Research. Prehosp. Disaster med 2017 Mar 09;32(3):329-332. [doi: 10.1017/s1049023x17000139]

16. Al-Harthi A, Al-Harbi M. Accidental injuries during muslim pilgrimage. Saudi Med J 2001;22(6):5.

17. Aitsi-Selmi A, Murray V, Heymann D, McCloskey B, Azhar EI, Petersen E, et al. Reducing risks to health and wellbeing at mass gatherings: the role of the Sendai Framework for Disaster Risk Reduction. International Journal of Infectious Diseases 2016 Jun;47:101-104. [doi: 10.1016/j.ijid.2016.04.006]

18. Toroyan T. Global status report on road safety. Injury Prevention 2009 Aug 03;15(4):286-286. [doi: 10.1136/ip.2009.023697]

19. Crawford T, McGrowder D. Road Traffic Injury Epidemic in Jamaica: Implications for Governance and Public Policy. ASS 2009 Feb 09;4(10). [doi: 10.5539/ass.v4n10p182]

20. Saadat S, Mafi M, Sharif-Alhoseini M. Population based estimates of non-fatal injuries in the capital of Iran. BMC Public Health 2011 Jul 31;11(1). [doi: 10.1186/1471-2458-11-608]

21. Runyan CW, Perkis D, Marshall SW, Johnson RM, Coyne-Beasley T, Waller AE, et al. Unintentional injuries in the home in the United States. American Journal of Preventive Medicine 2005 Jan;28(1):80-87. [doi: 10.1016/j.amepre.2004.09.017]

22. Kobusingye O, Hyder A, Bishai D, Hicks E, Mock C, Joshipura M. Emergency medical systems in low- and middle-income countries: Recommendations for action. Bull World Health Organ 2005 Sep 22;83(8):31 [FREE Full text] [Medline: 16184282] 
23. Sasser S, Varghese M, Kellermann A, Lormand J. Prehospital trauma care systems. In: World Health Organization , editor. www.who.int/iris/bitstream/10665/.../924159294X.pdf. Geneva -Switzerland: World Health Organization; Nov 2005.

24. Krug EG, Sharma GK, Lozano R. The global burden of injuries. Am J Public Health 2000 Apr;90(4):523-526. [doi: 10.2105/ajph.90.4.523] [Medline: 10754963]

25. Lyons RA, Brophy S, Pockett R, John G. Purpose, development and use of injury indicators. International Journal of Injury Control and Safety Promotion 2005 Dec;12(4):207-211. [doi: 10.1080/17457300500172776]

26. Odero W, Garner P, Zwi A. Road traffic injuries in developing countries: a comprehensive review of epidemiological studies. Trop Med Int Health 1997 May;2(5):445-460. [doi: 10.1046/j.1365-3156.1997.d01-296.x]

27. Ghaffar A, Hyder AA, Masud TI. The burden of road traffic injuries in developing countries: the 1st national injury survey of Pakistan. Public Health 2004 Apr;118(3):211-217. [doi: 10.1016/j.puhe.2003.05.003]

28. World Health Organization. Injuries and violence: the facts 2014. Geneva: World Health Organization; 2014.

29. Zeitz K, Zeitz C, Kadow-Griffin C. Injury occurrences at a Mass Gathering Event. Australasian Journal of Paramedicine 2015 Jul 14;3(1). [doi: 10.33151/ajp.3.1.307]

30. Razavi S, Ardakani H, Rajai S, Hollisaz M, Sadeghipoor H, Farshad A. Trends in prevalent injuries among Iranian Pilgrims in Hajj. Iran J Public Health 2011;40(2):5.

31. Riaz A, Shamspour N, Hollisaaz M, Tabatabaie, Saghafinia M, Shakeri M. Surgical admissions during the Muslims' journey of a lifetime.

https://www.researchgate.net/publication/277937934_Surgical_admissions_during_the_Muslims'_journey_of_a_lifetime 2013;1(1):e0005. [doi: 10.1057/9781137325273.0009]

32. Alfelali M, Barasheed O, Alshehri J, Bokhary H, Alsaedi S, Alhamzi A, et al. Foot Injuries Among Hajj Pilgrims with and Without Diabetes Mellitus: Implications for Infection Management. IDDT 2014 Oct 31;14(2):140-147. [doi: $10.2174 / 1871526514666140713160413]$

33. Saadat S, Soori H. Epidemiology of traffic injuries and motor vehicles utilization in the Capital of Iran: A population based study. BMC Public Health 2011 Jun 21;11(1):1-6 [FREE Full text] [doi: 10.1186/1471-2458-11-488] [Medline: 21693056]

\section{Abbreviations}

LMIC: low and middle-income countries

Edited by A Crawley, M Smolinski; submitted 25.04.18; peer-reviewed by Z El-Khatib, SA Khan; comments to author 21.12.18; revised
version received 19.04.19; accepted 18.10.19; published 28.05.20
Please cite as:
Chitheer A, Lami F, Radhi A, Arbaji A
Injuries Reported by Selected Health Facilities During the Arbaeenia Mass Gathering at Babel Governorate, Iraq, 2014: Retrospective
Records Analysis
JMIR Public Health Surveill 2020;6(2):e10877
URL: $\underline{\text { http://publichealth.jmir.org/2020/2/e10877/ }}$
doi: $\underline{10.2196 / 10877}$
PMID: $\underline{32463371}$

(C)Abdulaal Chitheer, Faris Lami, Ahmed Radhi, Ali Arbaji. Originally published in JMIR Public Health and Surveillance (http://publichealth.jmir.org), 28.05.2020. This is an open-access article distributed under the terms of the Creative Commons Attribution License (https://creativecommons.org/licenses/by/4.0/), which permits unrestricted use, distribution, and reproduction in any medium, provided the original work, first published in JMIR Public Health and Surveillance, is properly cited. The complete bibliographic information, a link to the original publication on http://publichealth.jmir.org, as well as this copyright and license information must be included. 